\title{
Observations during the Life of One Person Suffering with Schizophrenia and How to Deal with it
}

\author{
Salil Sood*
}

Submission: July 17, 2017; Published: July 31, 2017

*Corresponding author: Salil Sood, Richmond Fellowship Jyothi, 40-1/4, $6^{\text {th }}$ Cross, Vajpeyam Garden, Ashoknagar, BSK-1, Bangalore, Karnataka, India, Tel: 919535204511; Email: salilsood55@gmail.com

\section{Opinion}

Well it may seem farcical to say that one should relate to schizophrenia in such and such nameless way and behave in a particular fashion when one has a relapse. Nothing would be further from their minds than the severity of the symptoms and the instinctive reactions to them. This article is more for patient as well as the caregivers. However, if the subject were struck with the dreaded disease he would need to realize a few things about its effects, counter-effects, and challenges.

Firstly, I would touch upon the signs and symptoms leading up to schizophrenia. Every psychiatrist, many health care professionals, counsellors, and psychologists would give a boilerplate definition of schizophrenia and how it is led up to a pathologic form. Then they would give a set pattern of theories about how devastating it is and the various subtypes and its corresponding behaviour. But I have first-hand information since I've had schizophrenia (severe) at as early an age as 14 , and can relate to this problem much more easily than the professionals.

There are many factors which govern its onset. Firstly, if one is to understand why schizophrenia occurs then the most important thing one has to understand is that there is always a very significant period of depression preceding it. Depression occurs due to a series of trivial reasons (which seem significant to the person), as well as failures. Most of my frustrations occurred in school when was not conditioned to tackle the ignominy of a very competitive performance culture and syllabus, plus an ego not in consonance with my performance leading to a severe personality disorder. This was further compounded by high standards set by the institution and constant bullying.

What I'm trying to say is that school could be a central element in altering a student's personality. Which is why it is imperative for the caregiver to note signs in school days like depression, lethargy, lack of interest in studies or falling grades, lack of companionship, excessive brooding, greater penchant for sexual acts, and falling prey to substance abuse.
Again, when these above factors are considered the caregiver when he is alerted of any of these symptoms, he/she should immediately take cognisance of his ward and go to a psychologist first instead of a psychiatrist. A psychologist will be the best one to understand the subject and delineate any cognitive behaviour treatment requirements with abnormal behaviour which indicates pathology. The reason behind this is it that the psychiatrist sometimes might be myopic in his approach and might unnecessarily administer sizeable medications which would be disastrous in the long run.

In case of abnormal behaviour the psychologist would immediately recommend a psychiatrist. Then one should be given both a Mental Health Assessment test plus an aptitude test. If the patient scores low in both these forms of examinations then and only then should a patient be classified as mentally ill and can he given medications.

However, the role of the caregiver does not end here. One of the most important education and impacts the primary caregiver has to do is:

i. Not to cause any further stress to the ward who has been diagnosed with schizophrenia.

ii. To immediately withdraw him from school or college which could be causing him schizophrenia symptoms.

iii. Not to expect him to perform at any level, and most of all to tell him that nothing is expected of him.

iv. Give a brief background of his illness explaining to him that it is mainly because his brain is not functional.

v. Inform him in as compassionate a manner that they or his relatives will look after him forever.

vi. This underdog feeling in him will make his stress level much less and might actually make him perform to some degree of his satisfaction, because one of the most important 
causes of breakdowns and relapses are when the patient is comparing himself with his peers, and the expectancy his parents have of him.

There should be a treatment program for psychotic children's parents in which they help the child to develop further. They should be guided to react to the child's developmental disorder rather than cause it. Parents should be given demonstrations to focus on corrective approaches, competence motivation, cognitive and perceptual functions.

A very significant part of treatment is finding a suitable rehabilitation home and continual follow-up with his treating physician. Most of the mental illnesses are due to giving too much significance to performance of the patient and one's own imagined comparisons with his peers. The resultant effect of these conditions leads to heightened stress levels as well as which he is not able to cope with plus a retardation in psychological wellbeing. Wiser it would be that once the client is in a rehab home to tell him that he should not show his potential or excellence in any event lest it lead to excruciating circumstances where he has to perform at each and every stage.

I am not saying that one should limit the scope of progress of an entity. This is furthest from the case. The main reason I have suggested, which is the cause of schizophrenia, is that during the process of growing up the individual has received many inputs and most of them he has absorbed in his childhood What most caregivers don't realize is that they keep ushering the schizophrenia patient 'to do better', 'you're capable of it', 'you're very intelligent', 'a student who doesn't study becomes a cobbler', and all these types of unrealistic and idealistic fear inducing and complex creating ideations in a person. One must keep away from these false complex-enhancing statements, because they are all false and will create a negative impact on the patient. These are the stress triggers for students which lead to schizophrenia. This is because the caregiver is really gauging the patient from the artificially heightened struggle and makeshift achievement

This work is licensed under Creative Commons Attribution 4.0 Licens he has completed to keep him in sync with his family and peers expectancy, leading to an overestimated response to his abilities. However much you stress on a probable patient to go out and achieve for one who is dropping down the ladder of success, the more demoralized he will become. The best option would be to find out his real threshold verbatim and then let him grow on his own from scratch. But inform him without mincing words, that that they or this world expects nothing of him nor should he expect anything of himself. Since at that time he will have the luxury of staying in a rehabilitation home plus company of fellow patients and medicine monitoring, as well as psychiatrists, psychologists, and counselling professionals. Under this status quo it would be easier for the patient to find himself and get better.

One can never undervalue the importance of taking the medicine as prescribed by your physician. There is a strong bond between the suitability of the medication and the curable effect it has upon you. The medicine which the doctor prescribes is the underlying force behind getting better and remaining unstable and violent for the rest of your life. The medicine acts directly upon the patient's neurotransmitters in the brain and balance out the excess dopamine which is causing the mental illness. Sometimes it may take years to get the right admix of pharmacology, but it is worth it, because even in the event of the patient taking a slightly incompatible dose in the beginning the symptoms of the illness are greatly reduced.

Now I am 60 years old. I have lived almost all my life with this illness. However, I have been very fortunate to have got the perfect blend of a great rehab home with an assembly of very dedicated counsellors as well as an incredible doctor who has virtually cured me (even if we don't use the word 'cure' for schizophrenia). I am in remission for the last 7 years and for someone who was on the scale of 1 to 10 in critically ill during his formative year, I would choose 10. I can only hope for an equally generous state of affairs for all my fellow sufferers who have gone through this traumatic illness.

\section{Your next submission with Juniper Publishers will reach you the below assets}

- Quality Editorial service

- Swift Peer Review

- Reprints availability

- E-prints Service

- Manuscript Podcast for convenient understanding

- Global attainment for your research

- Manuscript accessibility in different formats

( Pdf, E-pub, Full Text, Audio)

- Unceasing customer service

Track the below URL for one-step submission https://juniperpublishers.com/online-submission.php 